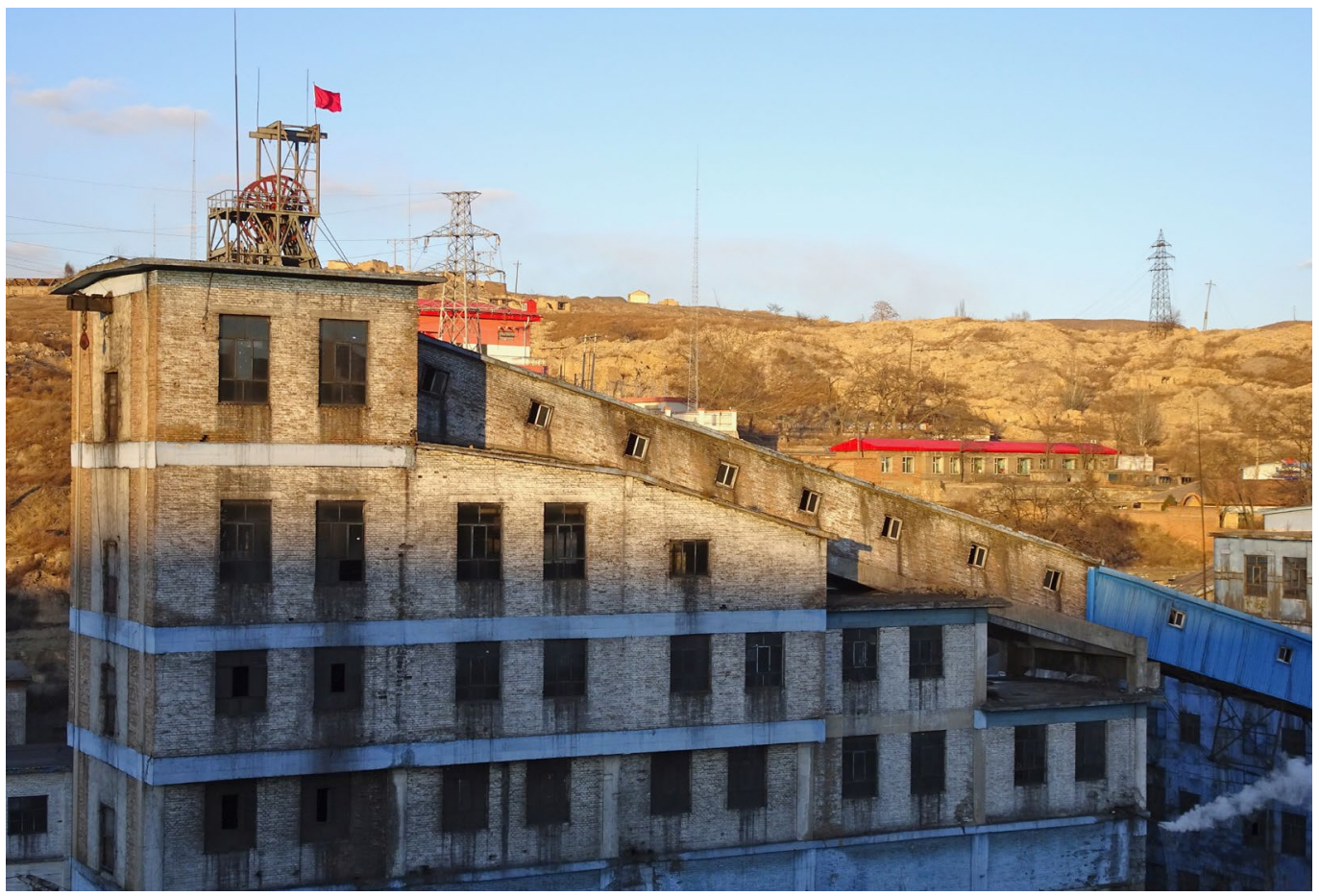

\section{The Coal}

\section{Transition in}

\section{Datong}

\section{An Ethnographic Perspective}

One of Tongmei's historical mines. Datong, February 2016. PC: Judith Audin.

Judith AUDIN

The city of Datong, Shanxi province, has long been known as the 'coal capital' of China. Through an ethnographic approach based on long-term observation and in-depth interviews conducted over several years, this essay examines how the restructuring of the local coal industry in the reform era has impacted the living and working conditions of the miners in the area.
Coal is the only sector we are good at. Here in Shanxi, the transition will be difficult, and it will take time too.

Interview with a Tongmei employee, Datong, 1 June 2016

Building a new Tongmei, inventing a new life. Tongmei slogan, April 2016

he coal industry represents a
key sector for China's national
economy and employment, and it is the country's main source of energy. Coal 
extraction has fuelled China's industrialisation and urbanisation throughout the twentieth and twenty-first century, especially after the liberalisation of coal production in 1979. In the reform era, the coal industry rapidly moved towards the market economy, oscillating along boom-and-bust cycles. After 2001, when China joined the World Trade Organisation, the new orientation towards a 'socialist market economy' driven by foreign direct investment triggered faster economic growth and rising living standards, as well as rising demand for coal production. Research in environmental studies, geography, and political economy has documented how the coal industry developed in China (Rui 2003; Wright 2012; Ho and Yang 2019). Since the mid 2000s, and more importantly since 2013, the coal sector has been restructured at the national level, following a new geography of production, and new measures aimed at 'de-capacity' (去产能) in the context of the promotion of new energies, as well as plans for 'low-carbon' and 'sustainable' development of 'resource-based cities' (资源性 城市) (State Council 2013; Woodworth 2015).

While labour sociologists have extensively documented two ideal-types of the Chinese working class-laid-off workers in state-owned enterprises (SOEs) in Northeast China and migrant workers in the 'world factory' (Lee 2007)-workers and communities of the Chinese coal industry have been overlooked. This lack of attention is unwarranted considering how the industry of coal extraction not only shapes territories, but also communities of workers whose livelihoods rely heavily on black gold' (乌金). Understanding coal contexts in contemporary China through an ethnographic lens illuminates the complexity of coal reform by examining embedded social processes. The underpinning idea is that coal, as a material, generates particular economies and infrastructures of extraction. It interacts with different scales of political power, producing specific histories, geographies, economies, and social and political systems that span from the local to international levels (Mitchell 2011). Because the material is extracted in situ, often in remote locations, the coal industry sustains specific, territorialised communities and social groups, and is at the core of local politicoeconomic systems in 'resource peripheries' (Hayter, Barnes, and Bradshaw 2003). Moreover, coal production, as a destructive industry, affects, undermines, and damages not only the environment through air pollution and land and water degradation, but also the people living in such places due to deadly accidents, respiratory diseases, and birth defects.

This essay aims to contribute to the sociology of coal mining in China by studying the social dimension of such profound restructuring in the city of Datong, an important coal cluster in the Jinbei (晋北) coal field. The article is based on long-term observation and in-depth interviews conducted in Datong from October 2015 until June 2019. Overall, this ethnographic approach 'from below' allows us to better understand the work and living conditions of coal miners, going beyond a simple image of hard labour and damaged landscapes.

\section{Spatialities of Coal}

Coal is embedded in temporalities-growth in boom and bust cycles-and in spatialitiesthe 'spatial system of the mine' (Baudelle 1994). Coal communities are closely connected to their territories of production, which are historically situated. Within the coal sector, my field research confirms that there are significant fractures in the identities of miners, between private and state-owned mines, between official employees (职工) and parttime employees (临时工), as well as between local and migrant workers. There are also differences in terms of systems of productionshaft mines, which is conducted through the excavation of a vertical or near-vertical tunnel from the top down, and open-cast mines where coal is extracted from an open pit-and coal regions, from Inner Mongolia, Shanxi, and Shaanxi to Sichuan, Jiangxi, Anhui, or Heilongjiang. By favouring selected coal 
regions along the Inner Mongolia-ShanxiShaanxi axis while excluding others, the current politics of the coal sector also greatly affects the workers' futures, shaping fulfilled and unfulfilled expectations (Ferguson 1999; Woodworth 2015).

The sensorial experiences of coal miners also depend on the local landscapes. For instance, Zhang Keliang, a miner-poet from Anhui province, described coal mining in his hometown in these words:

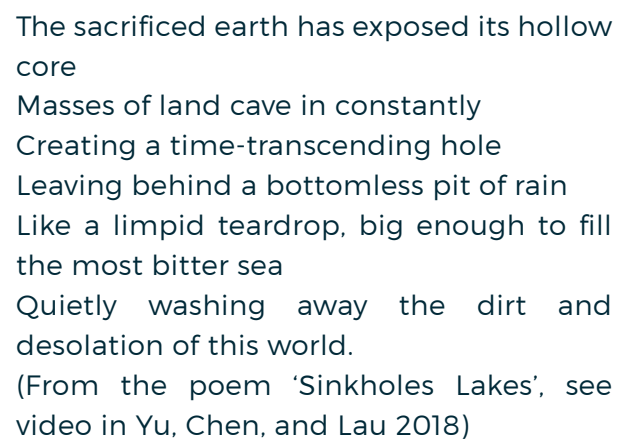

The topography of coal in Shanxi shows profound differences with Anhui, as described, for instance, in this collection of stories about one of Datong's early mines, Xinzhouyao (忻州 窑):

Xinzhouyao is the entrance gate on the western side of Datong. Two mountains oppose each other, forming a small excavation in the middle. Without the high-rise pit derrick and vehicles moving across, it would resemble one of the most common geological landscapes in northern Shanxi: on one side, there is an accumulation of yellow earth piled up for thousands of years; on the other, a mountain cliff stands tall; unknown wild grass grows over the mountain edge, and the wild wind continuously blows from all directions. (Zhou, Wen, and Tao 2009, 1, translated by the author)
The landscapes of Shanxi province, with the dry, yellow land of the Loess plateau, contrast with the rain-filled holes of Anhui.

Shanxi has been one of the core territories for coal production in China since the onset of Deng Xiaoping's economic reforms. To this day, Shanxi and Inner Mongolia remain the largest coal producers in China. At the same time, the industry has left deep 'scars' on both people and places in the province, producing labour victims as well as 'environmental refugees' (生 态难民) (Zhang 2013). In 2015, the coal-mining industry employed a significant proportion of the working population in the province, with Datong, nicknamed China's 'coal capital' (煤 都), holding a symbolic position as a 'resourcebased city' relying on a single industry.

Datong's mining district is located 12.5 kilometres southwest of the city centre. Densely-urbanised areas established along the coal railway give way to smaller villages spread along a river that has almost dried out, on sandy land and hills. At the centre of the mining district, Datong Coal Mine Grouphereafter Tongmei, the SOE that replaced the original Mining Bureau established in 1949-stands out as an important landmark for the city, both symbolically and physically. While specialising in coal mining and power, more recently Tongmei has begun dabbling in renewable energy, real estate, and cultural tourism. As we will see, along with the Datong city government, the company has been exerting a strong influence on the local territory and economy.

\section{Temporalities of Coal}

Roger Thompson highlights the specific historical trajectory of coal in Shanxi, starting from the early report of geologist and geographer Baron Richthofen, who wrote in 1870 that Shanxi 'is one of the most remarkable coal and iron regions in the world', and continuing to the early twentieth century, when Shanxi's coal became a symbol of local, 
provincial, and national unity (Thompson 2011,1262 ). In terms of production, unlike northeastern provinces such as Liaoning, Shanxi was not historically at the core of the coal industry in China in the early twentieth century (Wright 1984, 86-91), but rather developed rapidly in the 1930s. From 1937, under the Japanese military occupation, Datong turned into a new centre of coal production. In national history, the local coal industry is associated with forced labour and local Chinese miners are looked upon as martyrs and heroes of the resistance. In one of Datong's earliest mines, Meiyukou (煤峪口), the memorial of the 'hole of the ten thousand people' (万人坑) commemorates this history of mass graves. The Jinhuagong Coal Mine Museum (晋华宫国家 矿山公园) also celebrates local resistance, for instance by commemorating a strike that took place in 1941 at the Baidong (白洞) coal mine. However, my interviews with the miners go beyond the narratives of heroes and victims, with interviewees often mentioning with relative pride the early development of the local mining industry by Japan as a symbol of modern infrastructure and engineering.

During the Mao era, the Chinese coal industry was nationalised and almost all the coal was produced by state-owned mines. In Datong, in 1949 the Communist authorities established a new Mining Bureau (矿务局), which the following year controlled eight mines and one power station with a total of 3,000 workers (Gao and Song 1994, 6). After the launch of the economic reforms in the late 1970s, the coal industry produced profound transformations in the local geographical, political, and social structures as the coalfields provided new sources of income and new employment opportunities, reshaping the territories through the industrialisation of rural areas and the urbanisation of remote regions. In 1983, a new national policy allowed small-scale coal mines to develop under the principle that 'Large, medium, and small coal mines should develop simultaneously' (大中 小煤矿并举). The policy officially called for 'letting water flow as fast as possible' (有水快
流). Because of the uncertainty of the policies related to coal mines during the Mao era, mine operators seized on this opportunity, as they were not convinced it would last (Zhao and $\mathrm{Xu}$ 2012, 21). This initiated the diversification of local mines. At the end of 1990, 287 'local' coal mines were reported in Datong, classified in no less than nine different categories (Datong Statistical Yearbook 1991, 156). According to sociological research and to my interviews with local farmers, the coal production in Shanxi disrupted and dominated the land originally used for agricultural purposes (Zhang 2013).

In 1997, the Asian financial crisis resulted in a five-year slowdown of the coal economy and led the national authorities to launch a new policy to 'close the illegal and irrationallydistributed coal mines’ (关闭非法和布局不合 理煤矿) (State Council 1998). In an attempt to regulate the coal sector, governments at different levels tried to limit the number of private and collective coal mines. However, the implementation of this reform encountered serious obstacles, such as the resistance of local governments and officials worrying about the impact of such closures on the local GDP, as well as on mine owners (Wright 2007). Resistance also came from the workers themselves, whose livelihoods were highly dependent on the coal economy, especially in Shanxi province, where coal fields were located in remote regions without alternative sources of employment (Wright 2012).

The reform did not really achieve the reduction of illegal mines but it nevertheless contributed to improving safety measures. At the same time, SOEs experienced a new round of extensive reforms under the principle of 'keeping the large, releasing the small' (抓 大放小), which put much pressure on these companies to downsize, privatise, or even close (Rui 2005, 77). This led to a substantial number of workers being laid-off-with some estimating a 25 percent decrease in the number of workers employed in coal SOEs between 1996 and 2001 (Wright 2012, 146)-while others faced substantial cuts to their benefits. In my interviews, coal miners in Datong remember 
this 'difficult' (困难) period as part of the inevitable fluctuations of the coal industry. They added that soon after this period the coal industry was recovering and that the coal demand boomed from 2001, entering the 'golden decade' (黄金十年) of coal production.

\section{The 'Golden Decade' (2003-12)}

As key agents in the political economy of the coal industry, coal bosses (煤老板) appeared as the primary winners in the early 2000 s, in the context of a marketisation of all coal production units. Growing from small-scale capitalism in the rural private and collective coal mining sector, they were highly controversial figures; the high profits that the sector appeared to offer attracted much investment, especially from the Wenzhou region (Wright 2012, 98102). In Shanxi, during the mining boom the sector lacked a framework for safety protocols and other standards in environmental protection. Coal bosses could take advantage of the many loopholes and pay local cadres to get authorisations to open coal mines and to ensure their silence and complicity, while, on the other hand, the miners worked and lived in extremely poor conditions, risking-and losing-their lives to earn a living (Bollendorff and Ségrétin 2008; China Labour Bulletin 2008). Even state-owned mines, with their lower accident rates, did not have clear governance protocols, especially regarding the control of negative externalities-for instance in terms of pollution, living standards, etc. (Cao 2009). As a consequence of the 'crisis of governance', whether they were working in the public or in the private sector, the families of miners had low living standards in dangerous and polluted environments (Zhang 2013).

In the mid-2000s, safety issues in the workplace played an important part in the evolution of coal production. The politics of work safety and the scandal of mining accidents in China in those years factored in the decision of the Chinese authorities to eventually limit private and collective mines and to impose stricter controls on mining activity (Wright 2004 and 2007). In 2005, the central authorities issued new policies in favour of the development of large, publiclyowned coal bases such as Tongmei (see State Council 2005; National Development and Reform Commission 2007). The coal industry undertook a process of 'rationalisation' and was even able to survive the 2008 global financial crisis, due to a cold winter and to the Olympic Games that year (Thomann 2018). The next year, the coal sector was booming in the context of large investments in infrastructure (Wright 2012, 82). In addition, in 2008 and 2009 the provincial government of Shanxi implemented a small-scale mine closure policy. Large-scale public coal groups like Tongmei grew even bigger by bringing smaller mines under their umbrella, and ended up managing more mines and supplying most of the national production in a context of rising coal demand.

In the same period, living conditions became a field of social intervention by state-owned coal-mining enterprises. In 2005, the Datong city government, Tongmei, and the provincial government of Shanxi began to address the long-lasting 'social disaster' of mining-induced land-subsidence by implementing massive displacement and relocation measures (Zhang 2013). Despite issues in terms of compensation policy and other implementation problems, the move from mining 'slums' to apartment buildings and rising safety standards reinforced the loyalty of the workers towards the SOE (Yang, Zhao, and Ho 2017; Audin 2018). According to my interviews with Tongmei coal miners, the 'golden years' were beneficial to them, with monthly salaries going up to 10,000 yuan along with the provision of a more comfortable living environment (modern housing, public services, local amenities). According to my interviews, coal miners found opportunities to raise their families, make a livelihood, and access a form of stability as state-owned mine workers. 

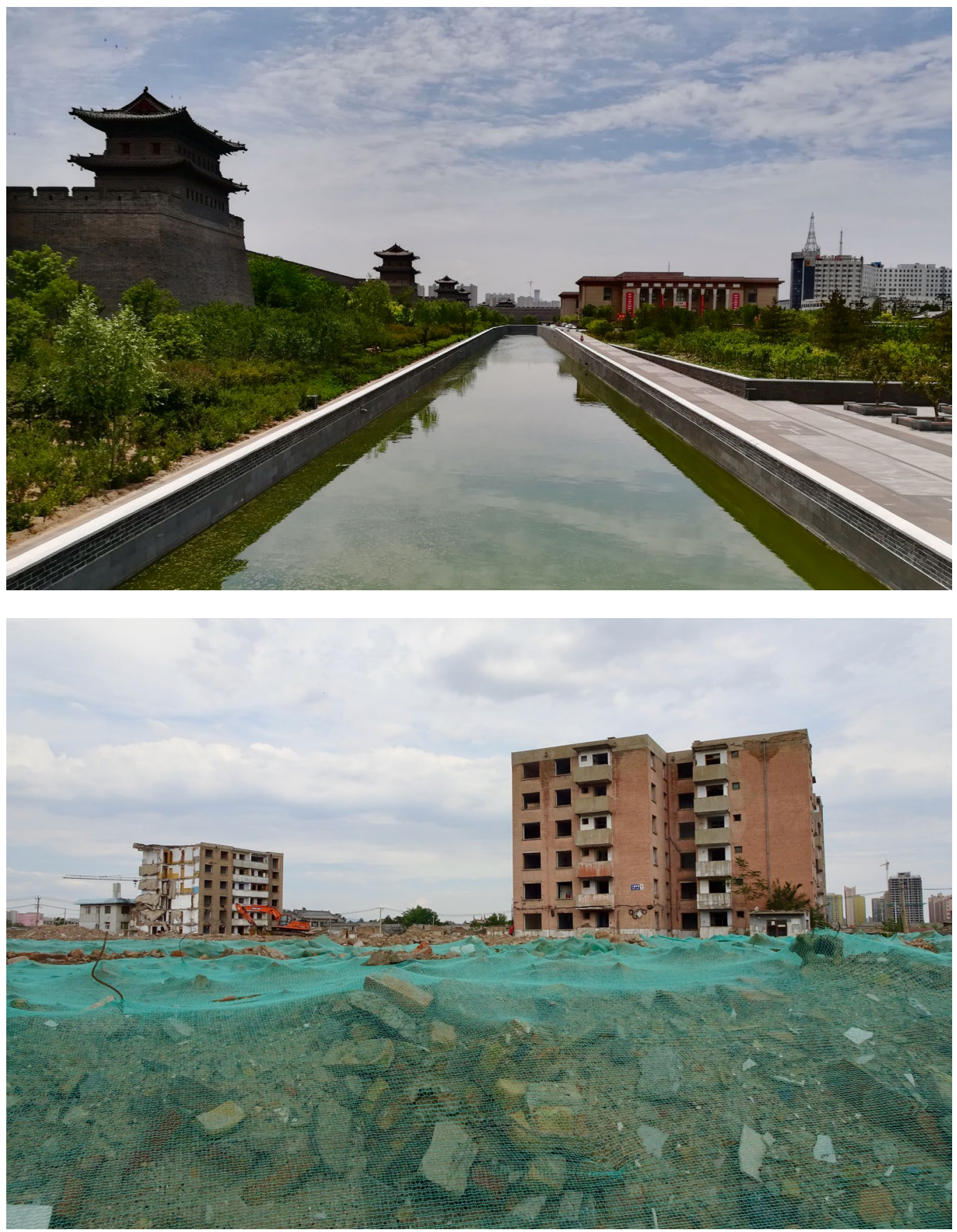

(Up) Datong 'new' ancient city. Datong, June 2019. (Below) Demolition in Datong city centre. Datong. June 2019. PC: Judith Audin. 


\section{Downsizing the Coal Industry}

In 2013 the price of coal fell, beginning a difficult period. In parallel, the central authorities announced new policy orientations for the energy sector, coupled with a proactive anti-corruption campaign targeting Shanxi province. New guidelines to promote more 'sustainable' (可持续) pathways of development were introduced, targeting the 'resource-based cities' mentioned at the beginning of this essay (State Council 2013). According to this document, cities that were too dependent on resource extraction and oversupply needed to diversify their economy and reduce their negative impact on the environment (see also the photo essay by Li 2018). In Datong, the development of the coal industry was based on systematic investments (and debt) in the coal sector, with coal enterprises actively moving towards specialisation and automation; the coal excess capacity benefitted the city government as a source of local GDP growth and tax revenue. Datong urban development itself was characterised by a high level of public debt.

In 2016 the Chinese government implemented strict de-capacity policies in order to increase the productivity of the coal industry and search for new pathways for development, including pollution reduction (State Council 2016). More precisely, in February 2016, the central government announced 1.8 million layoffs, 1.3 million of which were in the coal sector. These measures were announced along with the institution of a 100-billion-yuan fund by the central government aimed at facilitating the transition, but no clear agenda was published in terms of employment policy.

The implementation of this new policy is complex, with many unintended consequences due to the heterogeneous political status of coal mines. Only SOEs receive financial subsidies from the central government, and SOE mine cadres tend to comply with the policy, as they know that this will benefit their careers. In contrast, locally-owned private mines do not have the same incentives to comply (Shi, Rioux, and Galkin 2018). Moreover, as former policy reform programmes have shown in the past, policymakers at the provincial and local levels have different interest, which often create a mismatch in the implementation of such reform policies. The provincial authorities of Shanxi province were active in following the guidelines set by the central authorities in the Thirteenth Five-year Plan (2016-20) for the coal industry. The de-capacity measures targeted the mines with an output below 600,000 tons of coal per year. For instance, the provincial government announced the closure of 88 coal mines and a reduction of 69.2 million tons of production for the 2016-18 period. In 2019, it further announced another cut of 18.95 million tons of coal over-capacity and the closure of 18 more coal mines (Xinhua 2019). In 2016, according to a newspaper article, the Shanxi provincial government stated that out of 31,662 workers targeted as being cut off due to coal over-capacity, 31,586 had already been reassigned (Xinhua 2017). Tongmei Group chairman Zhang Youxi stated in October 2016 that 'there would be no laid-off worker' under the current de-capacity measures (CPPCC Daily 2017). But, from the coal miners' perspectives, such restructuring does produce immediate difficulties and future uncertainties.

The ways local communities cope with the coal transition are specific to each local context. For instance, in Heilongjiang, the coal miners of Shuangyashan mine, owned by Longmei-a state-owned group-went on strike to protest for their unpaid wages after the governor of the province, Lu Hao, publicly stated that miners had been paid on time despite the de-capacity measures (Wong, Chen, and Stanway 2016; Li 2016). The miners claimed they had not been paid for several months. As a result, Lu Hao apologised and promised to allocate more subsidies (Buckley 2016). Indeed, during my fieldwork in 2015-16, many miners from Tongmei confirmed they had late salaries and decreasing incomes. Yet in Datong, I did not witness any public protest, which does not mean that there was no tension 
on the de-capacity issue. Following the coal reform, Shanxi province-and Datong more precisely-are expected to remain one of the main hubs of coal production. Therefore, large entities like Tongmei are reinforced as major coal centres, concentrating production in their modern, productive, innovative model mines. At the same time, Tongmei Group still owns historical, old-style coal mines. The closure of small-scale coal mines and the restructuring of the industry did bring up serious challenges for Tongmei and the local workforce. With a labour force of approximately 200,000 employees, the sphere of responsibility of the enterprise includes a total of 800,000 people, including workers and their family members, not to mention the retired workforce. For example, the closure in 2016 of Tongjialiang (同家梁), one of Tongmei's historical coal mines represented an important symbolic event. According to regular field visits between 2016 and 2019, even if the workers were reassigned to work in other mines owned by Tongmei, they were very worried about the future. Moreover, the remaining residents of the closed mine area-farmers and retired miners-were deeply concerned about being left behind in a place of decay. But, overall, there was a strong sense of loyalty and relative confidence in Tongmei as a source of employment and livelihood. Even during difficult conjunctures, the miners thought it was 'too big to fail'.

\section{New Priorities}

Following the new policy of moving away from 'coal as the one and only source of power' (一煤独大), the city of Datong announced new green priorities, including a commitment to improve air quality under the slogan 'Datong blue' (大同蓝). The efforts to reduce air pollution produced some real outcomes, as the city ranked first for air quality out of 11 cities in Shanxi province in 2015. To boost economic growth, the city turned to new engines of development, especially tourism. In the mining district, there is strong emphasis on new power sources such as wind and solar energy. However, although Datong residents, including miners, appreciate the cleaner air and decongested road traffic in the city, these new sectors still rely heavily on public subsidies and employ fewer workers than coal production.

This rapid transition involved violent transformations and disparities in the city, especially in terms of social issues ( $\mathrm{Li} 2018$; Audin 2018). From 2008 to 2012, former Datong mayor Geng Yanbo launched the fast demolition/reconstruction of the city centre in order to build a new 'historical and cultural ancient city' (历史文化古城), a process documented in the 2015 film The Chinese Mayor by Zhou Hao (Kinkel 2017).

However, during the coal crisis, according to my observations, the project had slowed down. When coal prices took off again in 2017, urban planning projects followed, but at a slow pace (Audin 2018). During my latest field trip in June 2019, I noticed more active construction. The mayor's project was almost completed. Among other aspects, it was striking that most of the population had been evicted and relocated outside of the city centre. Inside the new 'ancient' city walls, the area is now fully dedicated to tourism. Tongmei also prepared for the coal restructuring mandated by China's energy policy by taking steps towards the 'heritagisation' of the mining land. In 2012, a coal mine museum officially opened to the public in one of Tongmei's historical mines, Jinhuagong (晋华宫), just across the river from the world-famous Yungang Grottoes. As late as 2008, Jinhuagong used to be a heavily polluted mining complex. The park was built on a 463-million-yuan investment: efforts at landscaping in the alleys of the mine park and the blue sky produce a contrasting, clean image. The originality of the place is that it is an active mine, where teams of workers come and go by the same entrance as the visitors, marked by a symbolic 'Long Live the Miners' slogan. 


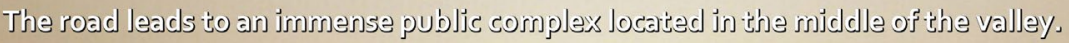

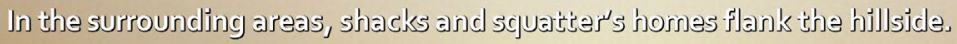

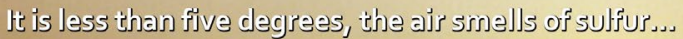

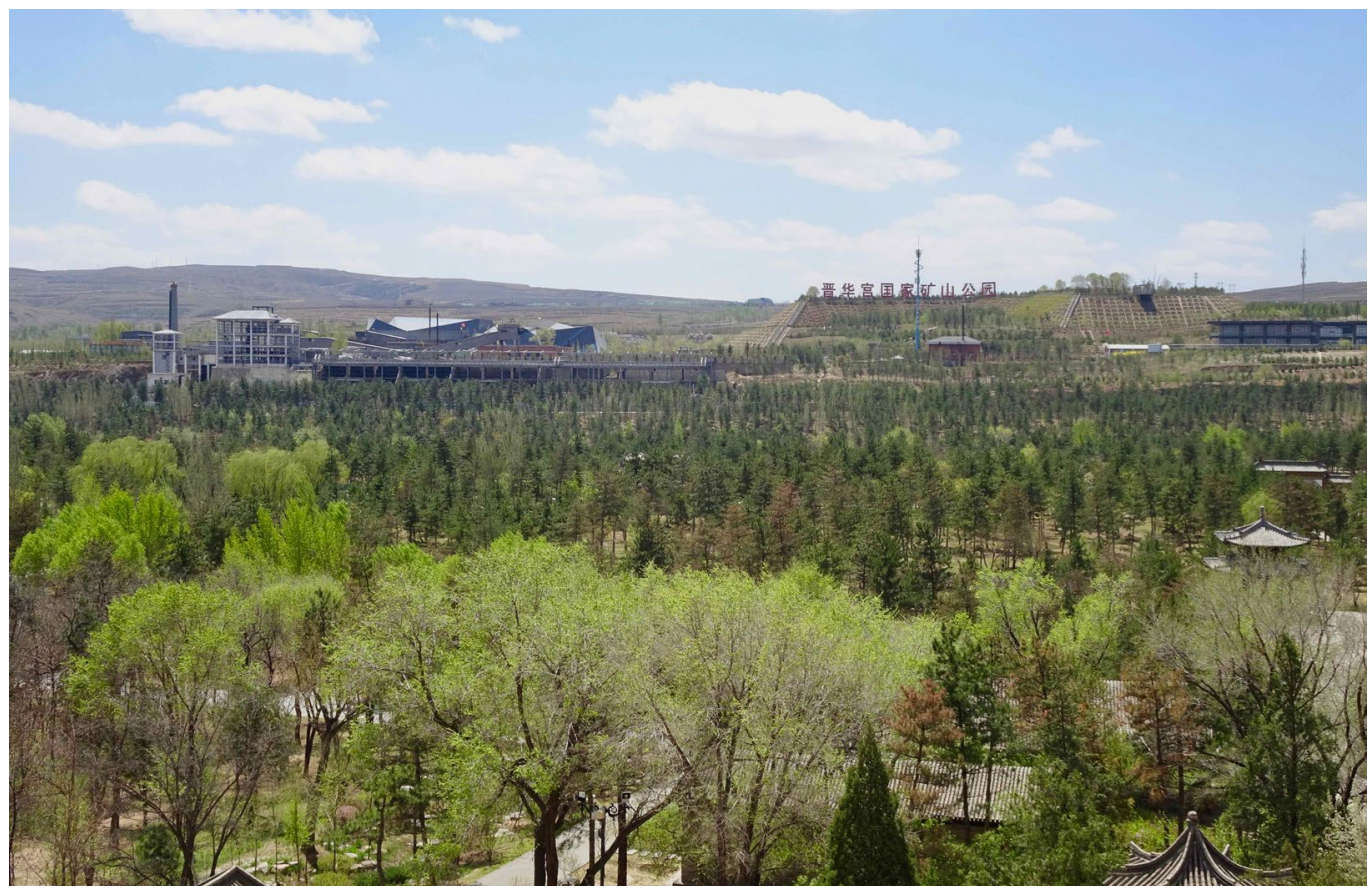

(Up) Screenshot of Jinhuagong mine in 2008 , taken from the web-documentary film Journey to the End of Coal (Bollendorf and Ségrétin 2008). (Below) Jinhuagong coal mine museum park. Datong, May 2017. PC: Judith Audin. 


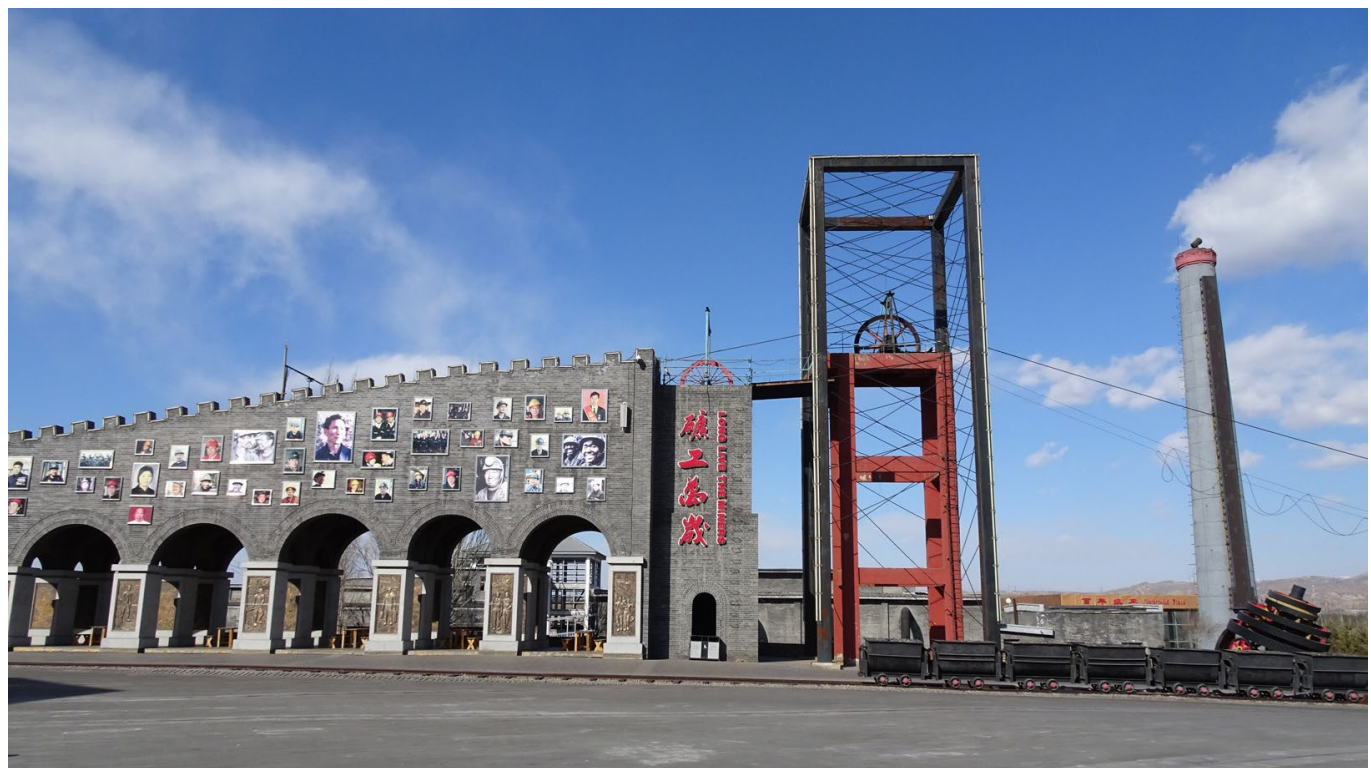

'Long Live the Miners' monument, Jinhuagong coal mine park. Datong, February 2016. PC: Judith Audin.

Despite these efforts, according to interviews with the staff that I conducted in 2016 and 2017, the park receives a low number of tourists apart from the relatives of coal miners in town for a visit. More generally, the issue of the reduction and reassignment of the mining labour force continues to cause concern among Tongmei workers, as neither the new renewable energy sector nor tourism seem to represent potential alternatives for such a massive population of workers. Moreover, reemployment issues are complex and involve the younger generations as well.

In conclusion, the political economy of coal mining in contemporary China shifted during the reform era towards the domination of 'giant' SOEs. During the 'golden decade', large state-owned mines took control of the coal industry in Shanxi and provided relative stability to the local coal community. This system was disrupted in 2013 during the coal crisis. Since 2016, in the context of the profound restructuring of the industry, de- capacity measures were developed under a complex nexus of power interactions at the global, national, and local scales. These interactions are having multifaceted impacts on the livelihoods of diverse groups of coal miners, which calls for more ethnographic research on the different coal communities in China.

\section{Acknowledgement:}

Research for this paper was funded by the MEDIUM project (Grant Contract ICI+/2014/348005) and the CEFC (Hong Kong). The author would like to thank Professor Chen Shuzhen at Shanxi Datong University, Professor Tim Wright for sending his book, and Dr Coraline Goron and Rachel Rong for their valuable comments. All shortcomings are my own. 
This text is taken from Made in China Journal: Volume 5, Issue 1, 2020, edited by Ivan Franceschini, Nicholas Loubere and Christian Sorace, published 2020 by ANU Press, The Australian National University, Canberra, Australia.

doi.org/10.22459/MIC.05.01.2020.04 